\title{
A CONTRIBUIÇÃO DE INTERVENÇÃO NO DOMÍNIO ECONÔMICO INCIDENTE SOBRE COMBUSTÍVEIS
}

RAFAELA MARCONDES DE CAMPOS

Acadêmico do curso de Direito - Centro Universitário Curitiba - UNICURITIBA. Curitiba - PR. email: ah rafah@hotmail.com

\section{VALGLACYR KESLLER DE CASTRO}

Acadêmico do curso de Direito - Centro Universitário Curitiba - UNICURITIBA. Curitiba - PR. email: val.kesller@outlook.com

\section{INTRODUÇÃO}

Desde os primórdios, é visível que, o Direito vem se modificando e se adequando as necessidades existentes que acompanham a sociedade no decorrer dos anos. Todavia, os valores sociais vão sendo transformados, e com estes vão sendo criados novos parâmetros para instituir normas jurídicas. Em grande parte, tais normas possuem cunho econômico, o que alimenta a necessidade da análise sistêmica do ordenamento jurídico do Estado e as transformações ocorridas no tempo, no que tange ao mercado e a interferência estatal. É função do Estado propiciar ao cidadão o direito de ter suas garantias protegidas, e dessa forma, é necessário enfrentar alguns desafios da estrutura econômica interna, e fomentar a livre inciativa e a livre concorrência com intuito de maior rentabilidade ao cidadão, distribuindo de maneira equânime os lucros e as receitas adquiridas por meio da contraprestação da tributação estatal sobre pessoas físicas e jurídicas para que o Estado participe da atividade econômica nos ramos de atividade onde não gera interesse a exploração da iniciativa privada. Nesse diapasão é possível que o sujeito passivo da relação jurídica tributária (contribuinte ou responsável), possa obter a 


\section{Personalidade Acadêmica Homenageada:}

Carlos Aurélio Mota de Souza (Universidade Ibirapuera - UNIB)

contraprestação específica do pagamento tributário devido ao sujeito ativo (Estado), que a Constituição Federal determinou ter competência tributária. Para isso precisase demonstrar a natureza tributária autônoma das contribuições especiais e comprovar a importância da finalidade para sua instituição e implementação no cenário jurídico brasileiro. O principal objetivo da intervenção do Estado é a efetivação dos princípios constitucionais demonstrando, assim, a qualidade de verdadeiros direitos fundamentais na imposição de limites constitucionais ao poder de tributar elencados na Constituição Federal. Fica evidenciado aqui que a definição de economia não está associada apenas a distribuição, e consumo de bens e serviços, mas também na atividade que o Estado se infere para que não haja lacunas no mercado, no qual ofertantes e demandantes operam o Sistema Econômico Nacional, com base nos princípios da Livre Iniciativa, e Livre Concorrência articulando sobre a função utilidade. Ademais, o objetivo que elucida esta pesquisa é: o detalhamento da contribuição de intervenção no domínio econômico incidente sobre combustíveis, por meio de conjecturas e análise da emenda Constitucional ํo 33, de $2001^{1}$, que definiu parâmetros de incidência do tributo interventivo in loco. Isso para procurar ajustar-se na regra matriz de incidência tributária, bem como confronta-lo com os princípios constitucionais da ordem econômica e do Sistema Constitucional Tributário, de forma a desvendar a finalidade interventiva dessa contribuição, investigando o tributo na análise do plano da validade em consonância com o texto constitucional. E para isso a Metologia adotada, partiu da análise de dispositivos no ordenamento jurídico brasileiro, de livros tanto físicos quanto eletrônicos, valendo-se assim do processo metodológico de revisão bibliográfica e de artigos científicos para assim expor quanto ao tema escolhido. Quanto aos resultados obtidos verificamos que desde os primórdios da civilização grega, houve a necessidade de compreender as palavras e seus significados, não fora diferente com a palavra "economia", cuja palavra é proveniente de dois vocábulos: oikos (casa) e nomos (norma, lei), traduzindo-se como a

1 EMENDA CONSTITUCIONAL № 33, DE 11 DE DEZEMBRO DE 2001. Disponível em : < http://www.planalto.gov.br/ccivil_03/constituicao/emendas/emc/emc33.htm>. Acesso em: 21 de out. de 2018. 


\section{Personalidade Acadêmica Homenageada:}

Carlos Aurélio Mota de Souza (Universidade Ibirapuera - UNIB)

administração de uma unidade habitacional, ou em tradução contemporânea seria a administração da coisa pública. Nesse contexto, percebe-se que a economia tem relação com a administração e gerenciamento da coisa pública. ${ }^{2} \mathrm{Na}$ Idade Média existiam algumas obrigações dos servos para os senhores feudais na época do feudalismo, os camponeses pagavam uma taxa para usufruir das terras para plantio, e em troca de mercadorias para sua própria subsistência, porquanto, além das taxas pagas aos senhores feudais, os camponeses davam maior parte da sua produção aos detentores do poder, ficando o mínimo de seu trabalho, para sobrevivência de suas famílias. A talha, corveia e banalidades são exemplos dessas taxas. ${ }^{3} \mathrm{Na}$ vigência da monarquia, a violência física e a tributação eram monopólios pessoais do rei. Devido a Revolução Francesa e o surgimento do Estado Moderno, o Estadoburguês, esses dois monopólios pessoais do soberano transformaram-se em monopólios públicos, no sentido de terem sido transferidos ao controle institucional da burguesia. ${ }^{4}$ No decorrer dos anos com o Estado Moderno, que inicialmente exerceu as atribuições de defensor da propriedade (ordem e tranquilidade públicas), da liberdade e do modo de produção capitalista, na passagem do século XIX para o século XX, recebeu as funções contemporâneas de substituição e compensação do mercado. Esses novos papéis do Estado foram-Ihe conferidos para o enfrentamento das mazelas sociais e econômicas provocadas pelo liberalismo, ou seja, pela incapacidade de o mercado se autorregular, o surgimento de monopólios e o exacerbado conflito entre capital e trabalho. Ao longo dos últimos 150 anos, o

2 PASSOS, Carlos Alberto Martins e NOGAMI, Otto. Princípios de Economia. São Paulo: Pioneira, 1998.

${ }^{3}$ A talha Era uma obrigação pela qual o servo deveria passar, para o senhor feudal, metade de tudo que produzia nas terras que ocupava no feudo. Se colhesse 20 quilos de batata, 10 quilos deveriam ser separados para o pagamento da talha. A corveia era a obrigação correspondia ao pagamento através de serviços prestados nas terras ou instalações do senhor feudal. De 3 a 4 dias por semana, o servo era obrigado a cumprir diversos trabalhos como, por exemplo, fazer a manutenção do castelo, construir um muro, limpar o fosso do castelo, limpar o moinho, etc.

A banalidade era obrigação que correspondia ao pagamento pela utilização das instalações do castelo. Se o servo precisasse usar o moinho ou o forno, deveria pagar uma taxa em mercadoria para o senhor feudal.

BRASIL, Sua Pesquisa. Disponível em: https://www.suapesquisa.com/feudalismo/talha_corveia_banalidades.htm>. Acesso em: 21 de out. de 2018.

4 SANTOS, Alessandro Lucas; KEMPFER, Marlene. Estado contemporâneo e intervenção no domínio econômico. Artigo científico, domínio público, 2012. P. 177. 


\section{Personalidade Acadêmica Homenageada:}

Carlos Aurélio Mota de Souza (Universidade Ibirapuera - UNIB)

Estado atua dentro do Mercado através do direito promocional, que tem o objetivo promover e estimular comportamentos para o desenvolvimento da economia. Como já elencado na introdução, o conceito de economia é a ciência social que estuda a produção, distribuição e consumo de bens e serviços, a fim de buscar maneiras de se possibilitar melhores condições de vida para a sociedade, satisfazendo as necessidades públicas, atendendo os anseios sociais. De acordo com Rosseti ${ }^{5}$ a economia é a ciência que estuda as formas de comportamento humano resultantes da relação existente entre as ilimitadas necessidades a satisfazer e os recursos que, embora escassos, se prestam a usos alternativos. Nesse sentido, a ciência econômica traz como tema central o problema da escassez dos bens econômicos, enquanto as necessidades são muitas, atuando de forma a viabilizar a maximização dos bens para atender às grandes demandas sociais. Apesar da função principal do Estado de buscar a efetivação do bem comum de todos, não se confunde com o conceito de economia. Todavia deve-se observar a interface entre o Estado e o Mercado. No decorrer dos anos, com a evolução dos modelos socioeconômicos ao redor do mundo, o Brasil passou a adotar um comportamento interventor nas atividades econômicas em detrimento de uma postura liberal que prega a não intervenção estatal na economia. Através da Constituição da República Federativa do Brasil, foi possível criar ferramentas para a intervenção do Estado na economia, denominadas de Contribuições de Intervenção no domínio Econômico (CIDEs). No qual, podemos dizer que são como subespécies das contribuições, disciplinadas nos termos do artigo 149 da CF. Tais exações tributárias proporcionam a intervenção do Estado no domínio econômico por meio da vinculação da destinação de suas receitas a determinadas atividades, visando incentivá-las. Com o advento da Emenda Constitucional ํo 33 de 2001, houve a inserção do $\S 4^{\circ}$ ao texto do artigo 177 da Constituição da República, e concomitantemente, a introdução de uma nova contribuição de intervenção ao domínio econômico, a chamada CIDE-combustíveis, contribuição que incide sobre a importação e comercialização de petróleo e seus

5 ROSSETI, José Pascoal. Introdução à economia. 17. ed. reest., atual e ampliada. São Paulo: Atlas, 1997. p. 52. 
Personalidade Acadêmica Homenageada:

Carlos Aurélio Mota de Souza (Universidade Ibirapuera - UNIB)

combustíveis derivados, gás natural e seus derivados e o álcool etílico combustível, intervenção que manifesta-se diretamente no mercado interno.

\section{CONCLUSÃO}

Encontra-se no presente momento na fase de desenvolcimento.

PALAVRAS-CHAVE: Tributo; CIDE-Combustível; Intervenção e Economia; Ordem Econômica.

\section{REFERÊNCIAS}

BRASIL. Emenda Constitucional № 33, DE 11 DE DEZEMBRO DE 2001. Disponível em : < http://www.planalto.gov.br/ccivil_03/constituicao/emendas/emc/emc33.htm>. Acesso em: 21 de out. de 2018.

Sua Pesquisa. Disponível em: < https://www.suapesquisa.com/feudalismo/talha_corveia_banalidades.htm> Acesso em 21 de out. de 2018.

CUNHA, Danillo Hamesses Melo; BEZERRA, Mariana Silva. CIDE- Combustíveis: Tributação indutora e desenvolcimento economico e ambiental. Revista Direito e Desenvolvimento. A.2, n.4, jul/dez. 2011.

HORVATH, Estevão. Contribuições de Intervenção no Domínio Econômico. $3^{a}$ ed. São Paulo-SP: Ed. RT, 2009.

PASSOS, Carlos Alberto Martins e NOGAMI, Otto. Princípios de Economia. São Paulo: Pioneira, 1998.

ROSSETI, José Pascoal. Introdução à economia. 17. ed. reest., atual e ampliada. São Paulo: Atlas, 1997.

SANTOS, Alessandro Lucas e KEMPFE, Marlene. Estado contemporâneo e intervenção no domínio econômico, artigo científico, domínio público, 2012.

VINHA, Thiago Degelo. A contribuição de Intervenção no Domínio Econômico 
Percurso - ANAIS DO VIII CONBRADEC

(Congresso Brasileiro de Direito Empresarial e Cidadania) vol.02, n.29, Curitiba, 2019. pp. 432-436

DOI: $10.6084 / \mathrm{m9}$.figshare. 8362373

Personalidade Acadêmica Homenageada:

Carlos Aurélio Mota de Souza (Universidade Ibirapuera - UNIB)

incidente sobre combustíveis e derivados. 207 f. (Mestrado em Direito) Universidade de Marília, São Paulo, 2006. 